\title{
Contribution of a Prosthodontist in the Field of Forensic Odontology
}

\author{
${ }^{1}$ MR Dhakshaini, ${ }^{2}$ Ashish Satpathy
}

\begin{abstract}
Dental records and forensic odontology is in use to identify victims. The earliest known example by dental means dates back to $66 \mathrm{AD}$. It relies on sound knowledge of teeth and jaws, possessed by dentist and incorporates dental anatomy, histology, radiography, dental materials and developmental anomalies. Forensic is derived from the latin word 'forum' which means 'court of law'.

Odontology $\rightarrow$ study of teeth. Defined as that branch of dentistry which, in the interest of justice, deals with the proper handling and examination of dental evidence, and with the proper evaluation and presentation of dental findings. Role of prosthodontist to identify and maintain dental records is becoming increasingly important.
\end{abstract}

Keywords: Forensic, Rugoscopy, Lip prints, Bite marks.

How to cite this article: Dhakshaini MR, Satpathy A. Contribution of a Prosthodontist in the Field of Forensic Odontology. Int J Prosthodont Restor Dent 2014;4(2):56-59.

\section{Source of support: Nil}

Conflict of interest: None declared

\section{INTRODUCTION}

Elaborate dental records including radiographs and spare crowns identified the body of Adolph Hitler, the most highprofile case of dental identification. ${ }^{1}$

Saddam Hussein's capture was verified using DNA sample from saliva. ${ }^{2}$ It creats a wave in our mind regarding time immemorial since dental records and forensic odontology is in use to identify victims. The role of forensic odontologist and prosthodontist in dealing various autopsy cases is becoming indispensable day by day. The integration of new technology into forensic science has given a lot to this mankind. The role of prosthodontics in forensic odontology:

- Sound knowledge of dental materials

- New ways of engraving records into prosthesis

\footnotetext{
${ }^{1}$ Professor, ${ }^{2}$ Postgraduate Student

1,2Department of Prosthodontics, JSS Dental College, Mysore Karnataka, India

Corresponding Author: Ashish Satpathy, Postgraduate Student Department of Prosthodontics, JSS Dental College, Mysore Karnataka, India, Phone: 9916242206, e-mail: simund2@gmail. com
}

- Study of rugae patterns - rugoscopy

- Impression making and models of bite marks

- Lip print recording and identification.

This paper reviews on various aspects of forensic odontology.

\section{DISCUSSION}

Forensic odontology contributes into forensics in the following ways:

\section{By Engraving Records in Prosthesis: $:^{3,6}$}

Labeled dentures can be important in identifying the owners in case of an accident, loss of memory, state of unconsciousness, being inadvently misplaced, or in identifying the bodies of those who have died in the calamity.

It is of two types as follows:

\section{Surface Methods:3,4}

Writing, scribing on tissue fitting surface or the polished surface with fiber-tipped pen, embossing initials of the patient in master cast with burs. It is not the permanent method. Engraving records on surface can cause food debris accumulation and infectons.

\section{Inclusion Methods: ${ }^{3}$}

They are permanent but time-consuming and requires skill.

- Paper strips: ${ }^{3,4}$ An inexpensive way is utilizing a piece of onion skin paper. The strip of scribed paper is placed between the ridge and center of the palate of the fitting surface of the denture is covered with resin before final closure of denture flask.

\section{ID band: ${ }^{3,4}$}

Dentures may be marked ${ }^{5}$ with stainless steel band. The most commonly used fire-resistant materials are titanium foil and HO matrix band containing an identifiable coding system reprinting patient details.

\section{Laser etching: ${ }^{3,7}$}

Copper vapor laser can etch patient identification in metal surface of partial dentures. The method is very expensive and needs special equipment and expertise. 


\section{T Bar: ${ }^{3,8}$}

A t-Shaped clear PMMA resin bar is constructed by cutting baseplate wax and then is flasked, packed, processed and finished in clear or pink PMMA. An identification printed label against the flat surface of the bar is fixed. It is then surface-polished to produce a clear window displaying the ID label.

\section{Electronic Microchips: $:^{3,9}$}

Patient information was etched onto a chip measuring $5 \times 5 \times$ $0.6 \mathrm{~mm}$. It is bonded with acrylic resin. Further advancement includes specialized equipment to transfer details to computer. Its disadvan-tage is that it can be inscribed only by manufacturer and not by the dentist.

\section{Lenticular System: ${ }^{3,10}$}

Lenticular lens is used to produce images with an illusion of depth, morph or the ability to change or move as the image is viewed from different angles. Information once written cannot be changed, may not withstand fire.

\section{RFID Tags: $:^{3,11}$}

A radiofrequency identification tag is a cosmetic, effective labeling method permitting rapid and reliable identification by the wearer size $-8.5 \times 2.2 \mathrm{~mm}$. Large amount of denture usage data can be stored in them.

Photographs: 2,12

Patient photograph is embedded to clear acrylic denture base. Useful in countries having low literacy rate. It was resistant only upto 200 to $300^{\circ} \mathrm{C}$.

Bar Codes: 2,13

Similar to bar coding of various other consumer goods. The bar code that is resistant to high termperatures is incorporated into a denture and sealed with heat cure acrylic resin.

\section{Chelioscopy: $:^{14-16}$}

The external surface of lips has many elevations and depressions forming a characteristic pattern called lip prints, examination of which is known as chelioscopy. In 1932, Edmond Locard, one of France criminologists recommended the use of lip prints in personal identification and criminalization. Suzuki and Tsuchihashi gave a new name to lip prints as - 'figura linearum labiorum rubrorum'.

Snyder reported in his book homicide investigation that the characteristics of the lips formed by lip grooves are as individually distinctive as the ridge characteristics of finger prints.

The methods to obtain lip prints are of two types:

- Direct method

- Indirect method

\section{Rugoscopy: ${ }^{16,17}$}

It is the study of palatal rugae - Caklas and Shetty, et al had reported palatal rugae were first described by Winslow in 1753. Palatal rugae are irregular, asymmetric ridges of the mucous membrane extending laterally from incisive papilla and the anterior part of the median palatal raphe.

Rugoscopy finds application in the field of anthropology, comparative anatomy, genetics, forensic odontology, prosthodontics and orthodontics. Palatal rugae, in addition to being unique to and individual, are protected from trauma by their natural position in the head and insulated from heat by tongue and buccal fat pads, unlike fingerprints which can get destroyed. With age, rugae change length but remain in the same position throughout the entire life of a person. To study rugae, impression of maxillary arch is made. Impression is poured with dental stone. Rugoscopy may not be so useful in crime scene investigation but very useful in necroidentification technique, especially in aeronautical accidents.

\section{Bite Mark Analysis: ${ }^{18-21}$}

Individual Bite Marks - The marks left by the teeth in a person may be used to identify an individual. The differences in size and shape of teeth can sometimes be easily noticed, especially when teeth are missing or prominent. The most common type of bite marks are contusions.

Bite marks can be in two- or three-dimensional evidence. Two-dimensional evidence like pictures have angular distortion. Some tools within Photoshop can be used to detect and correct for certain angular distortions. This is an extremely important step as it forms the foundation for the comparison procedures that follow. The first issue with this picture is the scale's off-angle position relative to the bitemark.

\section{DNA in Forensic Odontology: ${ }^{19}$}

The highly variable regions of DNA have unique patterns for each individual. Several biological materials may be employed for isolation of DNA and accomplishment of laboratory tests for human identification, including teeth, bone tissue, hair bulb, biopsy sample, saliva, blood and other body tissues.

\section{Sex Determination from Pulpal Tissue: ${ }^{19,22}$}

The sex determination from pulpal tissue is based on the presence or absence of X-chromosome. 


\section{STUDIES FOR AGE ESTIMATION AND SEX DETERMINATION ${ }^{19}$}

\section{Mandibular Canine Index as a Sex Determinant}

Canines seem to be unaffected by extreme catastrophic events like air crashes or hurricanes. The method comprises of evaluating dental casts in the age group of 14-20 years. Boaz, et al revealed that the mean values of the buccolingual and mesiodistal dimensions of the mandibular left canine were greater in females than in males and the mean values of the mesiodistal dimensions of the mandibular right canine in females were greater than that in males in the given sample.

\section{Cementum Annulations for Age Estimation}

The tooth cementum annulations may be used more reliably for age estimation. The predicted age of the individual is thus obtained as:

Number of incremental lines $(\mathrm{n})=\mathrm{X} / \mathrm{Y}$

where $\mathrm{X}$ is the total width of cementum from dentinocemental junction to cementum surface and $\mathrm{Y}$ is the width of cementum between the two incremental lines.

By adding average age of eruption in years for each tooth as presented in Gray's Anatomy, the counted number of incremental lines, the chronological age of the individual was obtained.

$$
\mathrm{E}=\mathrm{n}+\mathrm{t}
$$

where estimated age $=$ number of incremental lines $(n)$ + eruption age of tooth $(t)$.

\section{Enamel Rod End Patterns}

Enamel rod end patterns are unique to an individual tooth of the same individual and in different individuals.

Enamel rods are laid down by the ameloblasts in an undulating and intertwining path. This is manifested on the outer surface of enamel as patterns of the ends of a series of adjacent enamel rods. These patterns on the enamel surface are called tooth prints.

The term 'ameloglyphics' ('amelo' meaning 'enamel'; 'glyphics' meaning 'carvings') - has been used for the study of enamel rod patterns on tooth surface. These enamel rod end patterns can be duplicated by various methods like acetate peel technique, rubber base impression, etc.

The age-related changes in the dentition can be divided into three categories: formative, degenerative and histological. Formative changes can be good predictors till the age of 12. They include the completion of the crown, eruption of the crown into oral cavity and completion of the root. Degenerative changes include attrition, periodontosis, secondary dentin and cementum apposition (both seen microscopically), root resorption and transparency of the root seen in ground sections.
Amino acid racemization studies are also used to determine age.

Aspartic acid is most commonly used based on its presence in human dentin. Aspartic acid exhibits optical phenomena by existing in the dextro (D) or laevo (L) forms. L-aspartic acid is found in human dentin and with time converts into the D-aspartic acid. It has a slow metabolic turnover and, therefore, is slow to decompose. Thus, assessment of the $\mathrm{D} / \mathrm{L}$ ratios in dentin, by chromatographic techniques, can be correlated to age.

\section{Dentin Translucency ${ }^{19}$}

Dentinal translucency is considered best for dental age estimation.

\section{Panoramic Radiography ${ }^{19}$}

Dental examination and comparison between antemortem and postmortem dental records and radiographs produce results with a high degree of reliability and relative simplicity. Panoramic radiographs are also helpful to determine the age of the individual by assessing the stage of eruption.

The size of dental pulp cavity is reduced as a result of secondary dentin deposit.

\section{Third Molar for Age Estimation ${ }^{23}$}

The eruption stages were evaluated using the classification of stages by Olze, et al as:

Stage A: Occlusal plane covered with alveolar bone.

Stage B: Alveolar eruption; complete resorption of alveolar bone over occlusal plane.

Stage C: Gingival emergence; penetration of gingiva by at least one dental cusp.

Stage D: Complete emergence in occlusal plane.

Each individual age was calculated as date of exposure minus date of birth and recorded as years and 1/10 of years.

\section{Summary and Conclusions}

The contribution of a forensic odontologist in medicolegal proceedings cannot be overstressed. In spite of having progressed by leaps and bounds through various techniques in the identification of accident victims and in investigative criminology, forensic odontology is still bound by precincts. ${ }^{19,24}$ Humanitarian aims pursued by volunteering dentists during mass disasters should be refrained to assure quality work and high forensic standards. ${ }^{19}$ Guidelines and international principles and codes are needed especially when working in an international arena. ${ }^{19}$ This would allow disaster victim identification (DVI) teams from different nationalities to work in a synergic and universal way. Strategies for developing an international forensic odontology 
capacity and resources are needed for the management of dead bodies following a mass disaster, together with universal guidelines and codes. ${ }^{19}$

\section{REFERENCES}

1. www.anesi.com/east/bormann.htm.

2. Scientist 2003 Dec 19.

3. Data P, Sood S. The various methods and benefits of denture labelling. J Forensic Dent Sci 2010;2(2):53-58.

4. Stavrianos CH, Petalotis N, Metska M, Stravrianou I, Papadopoulos $\mathrm{CH}$. The value of identification marking of dentures. Balk J Strom 2007;11:212-216.

5. Alexander PMV, Taylor JA, Szuster FSP, Brown KA. An assessment of attitudes to and entent of the practice of denture marking in South Australia. Australian Dent J 1998;43(5): 337-341.

6. Berry FA, Logan I, Plata R, Riegel R. A postfabrication technique for identification of prosthetic devices. J Prothet Dent 1995; 73:341-343.

7. Ichikawa T, Hayasaki Y, Fujita K, Nagao K, Murata M, Kawano $\mathrm{T}$, Chen J. Femtosecond pulse laser oriented recording on dental prosthesis: A trial introduction. Dent Mater J 2006;25(4): 733-736.

8. Ryan LD, Keller JB, Rogers DE, Schaeffer L. Clear acrylic resin t-bar used in denture identification. J Prosthet Dent 1993;70:189190.

9. Richmond R, Pretty IA. Contemporary methods of labelling dental prosthesis: A review of literature. J Forensic Sci 2006;51: $1120-1126$

10. Colvenkar SS. Lenticular card: A new method for denture identification. Indian J Dent Res 2010;21(1):112-114.

11. Millet C, Jeannin C. Incorporation of microchips to facilitate denture identification by radio frequency tagging. J Prosthet Dent 2004;92:588-590.
12. Anehosur GV, Acharya AB, Nadiger RK. Usefulness of patient photograph as a marker for identifying denture wearers in India. Gerodontology 2010;27:272-277.

13. Nalawade SN, Lagdive SB, Gangadhar SA, Bhandari AJ. A simple and inexpensive bar coding technique for denture identification. J Forensic Dent Sci 2011;3(2):92-94.

14. Petersen, LC. Lip Prints (thesis submitted to the National University, La Jolla, CA, USA, March 2006 for Master of Forensic Science).

15. Saraswati TR, Mishra G, Ranganathan K. Study of lip prints. J Forensic Dent Sci 2009;1(1):28-31.

16. Sharma P, Saxena S, Rathod V. Comparative reliability of chelioscopy and palatoscopy in human identification. Indian J Dent Res 2009;20(4):453-457.

17. Paliwal A, Wanjari S, Parwani R. Palatal rugoscopy establishing identity. J Forensic Dent Sci 2010;2(1):27-31.

18. Bite Mark Identification (http://forensic-science-fall-2010. wikispaces.com/Bite+Mark+Identification).

19. Saxena S, Sharma P, Gupta N. Experimental studies of forensic odontology to aid in the identification process. J Forensic Dent Sci 2010 Jul-Dec;2(2):69-76.

20. Lessig R, Wenzel V, Weber M. Bite mark analysis in forensic routine case work. EXCLI Journal 2006;5:93-102.

21. Velden AV, Spiessens M, Willems G. Bite mark analysis and comparison using image perception technology. J Forensic Odontostomatol 2006;24:14-17.

22. Pretty IA, Sweet D. A look at forensic dentistry - part 1: The role of teeth in the determination of human identity. British Dent J 2001;190(7):359-366.

23. Olze A, Pynn BR, Kraul V, Schulz R, Heinecke A, Pfeiffer H, Schmeling A. Dental age estimation based on third molar eruption in first nation people of Canada. J Forensic Odontostomatol 2010;28(1):32-38

24. Kavitha B, Einstein A, Sivapathasundaram B, Saraswathi BTR. Limitations in forensic odontology. J Forensic Dent Sci 2009; $1(1): 8-10$. 